\title{
Reflections on the TEAM Trial: Why Clinical Care and Research Should be Reconciled
}

\author{
Jean Raymond on behalf of the TEAM collaborative group
}

\begin{abstract}
The current clinical and research environment is one that renders any true enquiry into the value of commonly performed surgical acts practically impossible. Drawing from the recent failure of Trial on Endovascular Aneurysm Management (TEAM), a trial on the endovascular management of unruptured intracranial aneurysms, I attempt to identify some principles that sustain the current ways of doing clinical research that have paradoxically become major obstacles to trials that aim to assess the potential benefit or harm due to interventions as currently practiced. Clinical research and practice must coalesce into "clinical care trials" if we are to provide patients with optimal, prudent care in the context of uncertainty. This may require a major change in the mentalities of clinicians, scientists, and patients alike, and the adoption of novel strategies for public agencies to support the integration of clinical research and care.
\end{abstract}

RÉSUMÉ: Réflexions sur l'essai TEAM: Pourquoi il faut conjuguer les soins et la recherche clinique. L'évaluation de la valeur réelle des actes chirurgicaux de tous les jours est devenue pratiquement impossible dans le contexte de recherche clinique actuel. L'échec récent de l'essai TEAM, qui portait sur le traitement endovasculaire des anévrismes, me sert d'exemple pour tenter d'identifier les principes sous-jacents aux façons de faire actuelles qui sont paradoxalement devenues des obstacles aux essais dont le seul but est d'évaluer les mérites, les bénéfices potentiels ou les complications, des interventions couramment pratiquées. La recherche clinique et la pratique doivent se conjuguer en 'essais de soins cliniques' si nous voulons offrir aux patients des soins optimaux et prudents en dépit du contexte d'incertitude. Ceci nécessitera des changements en profondeur de mentalité, tant chez les cliniciens et les chercheurs, que chez les patients, ainsi qu'une révision des rôles et des responsabilités des agences publiques, afin d'encourager l'intégration de la recherche clinique aux soins aux patients.

Can J Neurol Sci. 2011; 38: 198-202

\section{The TEAM story}

The Trial on Endovascular Aneurysm Management (TEAM) was a randomized controlled trial (RCT) that aimed to recruit 2000 patients with asymptomatic unruptured intracranial aneurysms (UIAs) to answer the following question: would elective endovascular coiling lead to a better outcome compared to watchful observation, over a period of ten years? The treatment tested had been performed since 1992; in 2006, the year TEAM was launched, it was - and remains - the most commonly performed neurovascular intervention ${ }^{1,2}$. Considering that the natural history of UIAs remains largely unknown ${ }^{3}$ and that treatment is 1) increasingly performed in proportion with the proliferation of diagnostic imaging for benign unrelated symptoms; 2) elective and thus carried out on healthy persons; 3 ) bears about $4 \%$ morbidity and mortality ${ }^{4}$; 4) does not eliminate risk of rupture ${ }^{4}$, and 5) has never been proved beneficial, the question asked was a clinically significant one, and to which no one could, and still cannot, give a convincing answer.
The Trial on Endovascular Aneurysm Management was supported by a grant from the Canadian Institutes of Health Research (CIHR), following positive assessment of the scientific merits of the trial, and the recognition that the answer to this question was valuable and needed. Two years later, the CIHR ordered the termination of the trial because "progress on this grant has been found to be unsatisfactory" and financial support was withdrawn. During those two years what was accomplished? Fifty registered sites had randomized 80 subjects out of the 2000 projected. A simple calculation cannot but

\footnotetext{
From the Centre Hospitalier de l'Université de Montréal, Notre-Dame Hospital, Department of Radiology, Montréal, Quebec, Canada.

Received June 2, 2010. Final Revisions Submitted August 26, 2010. Correspondence to: Jean Raymond, Centre Hospitalier de l'Université de Montréal, Notre-Dame Hospital, Department of Radiology, 1560 Sherbrooke East, Pavilion Simard, Suite Z12909, Montréal, Quebec, H2L 4M1, Canada.
} 
underscore failure: recruitment rate was 0.53 subject/site per year instead of the projected one subject/site per month. The CIHR ordered interruption of the trial five days before its first international investigator meeting, without consulting or even warning the Steering or Data Monitoring Committees (DSMC). The first lesson to learn from this experience is that working for years to seek (and obtain) support from federal agencies in no way renders secure a difficult clinical research endeavour. The CIHR's decision conflated interruption of financial support and trial continuation in a decision likely affected by conflicts of interest, a concern that could not be critically examined because there is no ethics committee to do so at the CIHR. Closer to the purpose of the present article, there are two ways to contest the unilateral judgment of the CIHR: 1) contest the validity of the process of inputting simple numbers into a feasibility equation without making allowances for important mitigating factors related to the increasing bureaucracy that plagues trials everywhere; 2) contest the logic underpinning the assumption that feasibility should be the discriminating factor in judging whether trials, (whose sole objective is to evaluate the value of current and entrenched practices to ensure better health outcomes following surgical interventions) should be funded. In what follows I will present my views in favor of point 2) above, and expose how the application of broad general principles that are currently held without considering the context has detrimental, counterproductive effects on health care. I do not question the principles on which current clinical research are based lightheartedly. My arguments are based on long and painful reflections. I speak, not as a trialist whose "baby" was denied the right to thrive, but as an interventionist confronted daily with questions asked by my patients, decisions that must be made, and actions carried out for which I have no rational reason to choose between the management alternatives at my disposal, beyond the personal gains obtained by indulging into an uncritical practice. More importantly I believe that the failure of TEAM is an opportunity to uncover a more fundamental, more pervasive problem that plagues modern medicine, which may explain why this type of clinical research is, at least most of the time, not even attempted, with grave consequences for patients.

\section{Questioning the received view}

Because the decision to stop or continue the trial should have been the responsibility of the Steering Committee, in consultation with the DSMC, I asked the following question to an eminent ethicist: Should TEAM sites continue to recruit subjects even in the presence of uncertainty regarding sufficient funding to complete the trial? His answer, in brief, was that recruitment could continue provided there was: 1) a reasonable probability of eventually securing financial support; 2) patient recruitment goals needed for reliable results could be realistically attained within a reasonable period of time; 3) collaborators were not becoming discouraged in sufficient numbers to jeopardize completion of recruitment and follow-up. This answer is at first glance ethically impeccable, at least according to the received view. However, a closer look at the implications of this statement is necessary. I am not questioning these principles in all cases, since they may be appropriate for research regarding proposed future practices that have yet to be incorporated into patient care, but I do question their application to that special type of research that aims to evaluate common medical actions that pose a non-negligible risk without ever having been rigorously assessed in regards to their benefits. To prevent any misunderstanding, I am not proposing that science should take precedence over ethics. I am resolutely claiming that science and ethics cannot be opposed the way they currently are when care and research are divorced, without grave consequences. In a few words, a good practice cannot be ethically right and scientifically wrong. I will examine each of the components of the ethicist's answer:

\section{There is a reasonable probability that funding can be found}

Once physicians, participating institutions, Scientific and Ethics Committees have agreed that the question being addressed by a trial is scientifically sound, ethically correct and clinically important, before recruitment of a single patient, how can the trial become scientifically or ethically suspect simply because funding is interrupted? Furthermore, should physicians, collectively uncertain about the clinical value of an invasive treatment, be required to await funding to test whether their routine daily practice, which costs 10 to 100 times as much, is beneficial? More fundamentally, if we believe (as I do) that carrying out this type of trial is the duty of the clinician, then why must we first compete for funding to assess the value of our treatments, when these exact same treatments are performed and health care costs covered on a case-by-case basis? Surely it cannot be that only the lucky or meritorious few should be permitted to fulfil their duty. Dollars certainly impact feasibility, a concept I will examine shortly, but dollars by themselves cannot dictate the science or ethics of a trial. Stopping a trial because funding is no longer available cannot be ethically or scientifically justified if the practice that was to be examined continues and the question is still clinically pertinent, the methodology sound, and the answer critical.

\section{The recruitment goal can be attained within a reasonable period of time}

When an intervention such as endovascular coiling of UIAs has been carried out in hundreds of thousands of patients, and for more than 15 years without any convincing evidence that it is doing good, what is the "reasonable time period" to reach a verdict? Are the patients recruited into the trial waiting for an answer? They were told this would take 15 years. We must remember they were offered participation in a trial that included two options that were equally 'good according to standard practice'. The crucial question is: Why should trials aimed at evaluating clinical care have a fixed, limited time period to provide an answer, in other words a "feasibility clause", while unjustified clinical care is allowed to enjoy an unquestioned, unlimited time of use?

\section{Enthusiasm, discouragement and feasibility}

I cannot understand how anybody supposed to promote science or ethics in medicine can request a feasibility clause (and all sorts of other requirements that I have no space to expose) for those, and only those clinicians willing to examine if their unjustified beliefs are true, thus encouraging physicians to stay out of trouble, and forget about the truth. Typically, ethical imperatives are difficult because they are designed to 
counterbalance some natural tendency to which human beings are prone. Medicine must be the only place in humanity where an ethical imperative is that easy: simply indulge your natural tendency to believe you know, you are good, you can act on unjustified beliefs, and get paid.

Feasibility cannot be scientifically assessed. It is a circular concept based on poorly justified beliefs that gain the power of self-fulfilling prophecies. If a trial is judged not feasible, collaborators are discouraged; if collaborators are discouraged, they do not recruit; if there is no recruitment, the trial is not feasible; if it is not feasible, there is no hope for funding; if there is no funding, there is no recruitment. This circle is selfdefeating; with TEAM, the no-confidence vote by the CIHR led to closure of the trial a few months later. Hence the story tells us what happens when the normative value of science are discarded in favor of 'feasibility', too often an excuse for poor methodology, for promoting research that is fast, easy and cheap, good for physician curriculum vitae, but in the end potentially misleading for patients. Doing the right thing is difficult, so let's proclaim it not 'feasible', then we will be able to justify our expediency and do wrong things. Conversely, the multiplicative virtues of circular beliefs, as used in sports, marketing and politics should also be used to promote trials: to complete a trial, we must believe the trial feasible; if feasible, then we can recruit patients; if we recruit patients, the trial becomes more and more feasible... until it is completed. There is however an important asymmetry in the use of this powerful but dangerous tool. For physicians, to believe, will or wish that treatment is beneficial (without evidence) is wrong, while to believe, will or wish that the trial is feasible, is right.

\section{The duty of research as the best way to care for current patients}

Should we really have to rely on marketing tactics in order to provide reliable answers on how to manage our patients, as I have just indicated? For sure, trials are hard. For physicians, to participate in trials evaluating their current practice should be considered a professional duty. Is it really a surprise that medicine could be difficult, and that fulfilling our duty requires effort? Trials should not be done because they are feasible, but because they are necessary. Necessary to advance science? No, scientific advancement by itself is rarely a necessity. Trials are necessary to protect current patients confronted with a lifeimpacting decision or a momentous clinical dilemma. I am not talking about some sort of societal duty, for advancing the field (although this may also be true). I am talking about a duty of prudence and veracity for the very same patient being considered for treatment. A most pervasive misconception regarding trials is that they are solely designed to seek a solution for the sake of future patients. Implicit in this misconception is the presumption that by participating in a trial, current patients are missing something - but what, exactly? A good bet is that in trials patients are allocated to treatment options by randomization instead of "individualized, case by case reasoning" and "personal preferences". But this reasoning is false: enrolment is offered, if appropriate, on a case by case basis; and it is because physicians and patients remain free to act on personal preferences that recruitment is so slow. This conception must be a heritage from the past. It is as if leaving our beliefs unquestioned was more valuable than finding out it they are true; as if doing something, anything, was more valuable than verifying whether it does good or harm. When the best course of action remains unknown, the choices are not between doing research or not. The choices are between doing the experiment within a well designed, declared research context, or doing the experiment outside any control, any normative frame, disguised as case by case reasoning. When the trial is stopped, what alternative are we left with? The status quo: to force physicians and patients into choosing one option and perform unproven interventions on a large scale. Under those conditions, "clinical research" consists at best in collecting outcomes in a registry, publishing the inevitably biased results with all sorts of statistical adjustments attempting to compensate for poor methodology 5 , and then admit after the fact that we were doing human research without the true consent of participants. In trials designed to evaluate current interventions, we are not exploring nature, trying to disentangle confounders to discover some hidden causal law behind observed phenomena. Clearly this methodology, where patients and treatments are variables and exposures, was invented by non-clinicians. Patients are not exposed to treatments the way they are exposed to mercury or high-voltage magnetic fields. Clinicians care for patients and the treatments we perform are actions over which we must have control. Hence, it is always "feasible" to compare what happens when we act to what happens when we don't; to see if we do good or harm, before we recommend a course of action. The principle of prudence (primum non nocere) asks us to use treatments that have been shown beneficial. When a treatment remains unproven, and especially when it might actually be harmful, this principle requires us to either refrain from performing it, or only do so within a carefully controlled, transparent context. No one should ignore by now how often medicine has misleadingly proposed harmful treatments in the past.

What do trials offer exactly to current patients, before meaningful results are even conceivable? Randomized trials offer current patients protection against poorly justified beliefs, wishful thinking, marketing and conflicts of interests. These forces are simply too strong to be left without any control. Any rapidly evolving field trials offer patients a chance to escape the temptations of fashion, overly-optimistic perspectives, rosy performance self-evaluations, learning curves, the quest for the largest case series to be presented at the next expert meeting, and so on... Observational studies will never offer this protection to patients. In the context of uncertainty, what is the best clinical care a physician can offer a patient? A randomized trial, with methods designed to minimize human error, to control biased opinions, extraneous interests, abuse of power and the temptations of uncontrolled human experimentation. But a first necessary step is to accept and acknowledge the uncertainty. This will require a fundamental change in mentalities. The main obstacle to recruitment is a certain culture. Clinicians are trained to perform, usually by imitation along an apprenticeship model, actions in a repetitive fashion. In a clinical world where research is excluded, suspension of judgment cannot exist. To each patient corresponds a (felt) most-appropriate action, which then becomes mandatory. Hence we are trained and certified to believe that we know, even when we do not. Our unjustified assurance finds resonance in patients, who hate hearing from 
their doctors "I do not know". But what are the consequences? In a clinical world where research is excluded, therapy can never be proved wrong. How is it then possible to define what is a good practice? The way to break this circle can only be an ethical imperative for all those proposing unproven interventions: treatment may be offered, when clinical judgment indicates, but only within the context of an RCT.

\section{Clinical care trials}

If some trials, no matter how difficult, are an essential part of offering best possible care to patients in the context of uncertainty, the process must be widely supported and greatly simplified. Yet they must meet some requirements. This is not the place to defend each point of the design; a simple rule of thumb can be applied at each step, however: Is this step conceived to protect the interest of the current patient confronted with the dilemma? In general, clinical care trials can be sketched as simple, multicenter, randomized trials integrated to daily practice. Where there is the practice, there is the trial, since we should not offer these treatments outside RCTs. Clinical care trials should address a true clinical dilemma for which the choice between options is momentous. Public agencies or professional associations could serve to identify which part of a practice should be performed within such a trial context. Selection criteria should be loose, to assist most current patients confronted with the problem. The trial should not obstruct clinical care, and should not entail extra tests or risks beyond what is necessary and proven to be beneficial. Endpoints should be pre-defined, simple, clinical, meaningful, valuable and resistant to bias. Follow-up visits and tests should be "routine', imposing a minimal (if any) burden on clinical transactions. Data should be collected in simple case-report forms filled by physicians or patients. The outcomes should be reviewed by an independent data monitoring board concerned with the safety of patients. If these characteristics are respected, there is no need for separate funding, for time-consuming contracts, for legal or bureaucratic pestering that will inevitably interfere with the goal of the trial: to help physicians provide prudent care in a context where evidence is lacking.

No matter how often we reminded people that TEAM consisted of currently used treatments with randomized allocation, plus anonymous web-based reporting of clinical outcomes, this was research, and therefore required applications to multiple committees. No matter how minimal the monetary compensation TEAM provided to participating sites, many institutions (including my own) insisted on negotiating contracts that were supposed to reconcile all the legal diversity of the world with zero risk tolerance. This of course is time consuming and illusory. Is this process helping patients? I now believe contracts between institutions and countries must be avoided at all costs. If to do so financial transactions must be eliminated, then so be it. Clinical care trials are not business arrangements between institutions; they are a national or international community of duty-bound physicians trying to properly care for patients.

\section{The role of public agencies}

If I am right in saying that clinical care trials are a duty for physicians engaged in the practice that needs to be appraised, the consequences are far-reaching. To make agencies aid rather than impede clinical research, major changes are in order: a) To prevent conflicts of interests and contradictory actions, decisions to approve clinical trials and funding must be independent; b) The agency should be in a position to support the principle that this type of clinical trials is not a luxury, but a necessity. To avoid a self-defeating process, peer-review cannot be a competition. It should serve as a consultation table to provide expert advice to improve proposed clinical care research; c) Trials are not feasible or unfeasible; they are necessary or not. If a hundred necessary trials are submitted, than a hundred trials should be designed and approved in a timely fashion; d) Necessary trials in difficulty need help, not termination. Knowledgeable help from an expert bureau is urgently needed; e) The agency should examine one by one all of the obstacles to clinical care research in a vigorous attempt to eliminate them. Here are a few items on the list: i) publish lists of trials the agency recommends; ii) provide official support for individuals trying to get a trial approved locally; iii) provide guidelines that prevent institutions from charging fees to examine clinical care research protocols; iv) have a legal research team examine the real necessity, if any, for contracts between institutions; v) offer expertise in the design of clinical care trials; vi) work with other national agencies to facilitate international collaborations; f) The agency should devote the few resources it has to teach the importance of this type of clinical research at all levels (physicians, institutions and the general public) using all potential aids, including advertisement, to promote the cultural revolution that will make these trials an integral part of optimal clinical care.

\section{Conclusions}

\section{Doing things differently}

Science and ethics work together. They must be an integral part of a good medical practice. Medicine today is artificially divided into, on one side, a clinical world composed of clinicians dedicated to the care of individual patients, required to act despite the lack of evidence, trained not to question their own decisions or to reliably evaluate their results while still being supported by unrestricted resources, and, on the other, a world of research dealing with uncertainty, perceived as a strange intrusion into care, severely obstructed by competition and bureaucracy, and supplied with only scant resources. This can only lead to bad research and to care that remains impossible to evaluate. Reconciliation of these two worlds is in order, and the required path is clear. There is only one real world of doctors trying to responsibly care for patients in a context where knowledge has yet to obtain. Clinicians must reconquer the science and the ethics of their practice. There is simply too much work to do and too much at stake for our patients for us to leave the state of clinical research as it is. It is incumbent upon us as physicians to lead the way into the future, a future where patients either receive care that is guided by evidence or are treated with as-yet unproven therapies under the protection of a welldesigned randomized clinical trial.

\section{ACKNOWLEDGEMENTS}

The authors thank Ruby Klink, Tim Darsaut, and David Roy for suggestions, comments and corrections of multiple versions of this manuscript. 


\section{REFERENCES}

1. Raymond J. Managing unruptured aneurysms: the ethical solution to the dilemma. Can J Neurol Sci. 2009 Mar;36(2):138-42.

2. Raymond J, Molyneux AJ, Fox AJ, Johnston SC, Collet JP, Rouleau I; the TEAM collaborative group. The TEAM trial: safety and efficacy of endovascular treatment of unruptured intracranial aneurysms in the prevention of aneurismal hemorrhages: a randomized comparison with indefinite deferral of treatment in 2002 patients followed for 10 years. Trials. 2008 Jul 16;9(1):43.

3. Raymond J, Roy D, Weill A, et al. Trial on Endovascular Aneurysm Management (TEAM) collaborative group. Unruptured intracranial aneurysms: their illusive natural history and why subgroup statistics cannot provide normative criteria for clinical decisions or selection criteria for a randomized trial. J Neuroradiol. 2008 Oct;35(4): 210-6. Review. 